Dicenda. Cuadernos de Filología Hispánica

ISSN: 0212-2952

http://dx.doi.org/10.5209/DICE.57709

\title{
El discreto desencanto de la burguesía o contra la crítica oficial de la Transición: Cercas, Reig y Pérez Andújar ${ }^{1}$
}

José Martínez Rubio ${ }^{2}$

Resumen. Este artículo analiza algunos de los conceptos que han construido en los últimos años el discurso crítico de la transición ('consenso', 'reconciliación', 'impunidad', 'operación de élites') y cuestiona las narrativas que conciben el periodo como impostura (Javier Cercas) o engaño (Rafael Reig), frente a otras que lo conciben como conquista de la clase obrera (Javier Pérez Andújar), desarrollando así otro concepto de 'democracia'.

Palabras clave: memoria; transición; Javier Cercas; Javier Pérez Andújar; Rafael Reig

\section{[en] The Discreet Disenchantment of the Bourgeoisie, or Against the Official Criticism of the Spanish Transition: Cercas, Reig and Pérez Andújar}

\begin{abstract}
This article discusses some of the concepts that have built in recent years the critical discourse of the transition ('agreement', 'reconciliation', 'impunity', 'elites operation') and it questions the narratives that conceived the period as imposture (Javier Cercas) or deception (Rafael Reig), compared to other stories that view it as conquest of the working class (Javier Perez Andújar), developing another concept of 'democracy'.
\end{abstract}

Keywords: memory; transition; Javier Cercas; Javier Pérez Andújar; Rafael Reig.

Sumario. 1. La crítica de la Transición antes y después de la crisis de 2008. 2. El relato oficial y la crítica oficial de la Transición. 3. La última impostura.

Cómo citar: Martínez Rubio, J. (2017). El discreto desencanto de la burguesía o contra la crítica oficial de la Transición: Cercas, Reig y Pérez Andújar, Dicenda. Cuadernos de Filología Hispánica, 35, 227-245.

\footnotetext{
1 Este artículo se inscribe dentro del Proyecto Prometeo 2016/133 dedicado a las confrontaciones de la memoria histórica y financiado por la Generalitat Valenciana.

2 Universitat Jaume I, jorubio@uji.es
} 
De muy pequeño la democracia fue para mí eso. La gente de los bloques defendiéndose. O quizá atacando. Los viajes en el ciento veintisiete de mi padre por las fábricas de Vallès para asistir a las charlas que daban los sindicalistas los sábados, los domingos. Hileras de obreros sentados en sillas plegables escuchando a otro como ellos que les animaba a seguir al pie del cañón y les explicaba de qué modo hacía él las cosas. A la democracia yo la he visto de niño salir de los barrios y de los polígonos.

(Pérez Andújar, Paseos con mi madre)

\section{La crítica de la Transición antes y después de la crisis de 2008}

Desde el principio, y quizás con un acierto instintivo, las protestas ciudadanas indignadas a raíz del 15 de mayo de 2011 se vincularon en el imaginario colectivo a los años de la Transición Española (Labrador, 2014). Sugerían con ello una suerte de fin de ciclo dentro de la recobrada democracia, cuyas manifestaciones o acampadas evidenciaban una sensación de agotamiento político, histórico y cultural derivado de la crisis económica. Tales protestas estuvieron protagonizados en su gran mayoría por una generación de ciudadanos nacidos o crecidos en democracia que pretendía retomar las riendas de la historia, reclamar un papel histórico dentro de ella, o al menos ir más allá de la historia nacional heredada, de sus instituciones y de sus discursos legitimadores del poder democrático (Martínez Rubio, 2013). No en vano la plataforma convocante de la gran manifestación del 15-M, que dio lugar posteriormente a todo un conjunto de réplicas, de acampadas y de conformación de colectivos de distinta índole, tenía por nombre "Democracia Real Ya"3; se sobreentendía entonces que el núcleo de la protesta radicaba en el concepto de "democracia", en su funcionamiento institucional y en su capacidad de identificación con la ciudadanía; instituciones y conceptos cuyas bases radicaban, indiscutiblemente, en la Transición española.

A partir de entonces, cada vez más voces han venido reclamando que el Estado inicie una "segunda transición" (Vicenç Navarro, 20125; Ramoneda, 2013), especialmente con el desarrollo del proceso soberanista catalán, lo que significaría la reactivación en la actualidad de otro factor determinante en aquella "primera" Transición: el encaje territorial a nivel administrativo de las nacionalidades históricas. Pero también han sido fundamentales la crisis económica desde 2008, así como la irrupción de partidos políticos de nuevo cuño, especialmente en el espectro de la izquierda (en concreto Podemos o las diferentes agrupaciones y movimientos autonómicos: Catalunya sí que es pot, En marea, Compromís, etc.), ajenos por completo a la terna de partidos clásicos que ha dominado el panorama político desde los años setenta. Esta conjunción de factores explicaría la iniciativa del Partido Socialista, el cual registró una petición a la Mesa del Congreso de los Diputados el 4 de diciembre

\footnotetext{
http://www.democraciarealya.es/ En otro estudio expuse el agotamiento de la teoría del fin de la historia, y de la vuelta a los conflictos de la Modernidad y a la reconstrucción de nuevos proyectos sociales. Cfr. Martínez Rubio, José (2014a): El futuro era esto, Villeurbane, Orbis Tertius.

5 http://blogs.publico.es/vicenc-navarro/2012/09/24/la-necesidad-de-una-segunda-transicion-y-una-nueva-constitucion/

6 http://elpais.com/elpais/2013/01/24/opinion/1359044816_490828.html
} 
de 2014 para la "creación de una Subcomisión, en el seno de la Comisión Constitucional, para abordar el estudio de la reforma de la Constitución" " al considerar que la "crisis institucional" había puesto fin a la vigencia de la Constitución del 78 y era necesario actualizarla en tres aspectos por este orden: 1. Blindar la cobertura social pública, y los presupuestos derivados a servicios sociales, sanidad y educación; 2 . Mejorar el sistema de representación de las cámaras legislativas y ampliar los espacios de participación en la toma de decisiones políticas; 3 . Revisar el modelo de Estado y articularlo como un Estado Federal. Una "segunda Transición" fueron las palabras con que se presentó por carta a la militancia ${ }^{8}$ el por entonces Secretario General del Partido Socialista tras imponerse en las primarias a Eduardo Madina y José Antonio Pérez Tapias y tras ser ratificado el resultado en el Congreso Extraordinario del PSOE en julio de 2014, y que debería acometer diversas reformas en el modelo económico del país, el modelo territorial y el modelo institucional ${ }^{9}$.

Es significativa la asunción de esa necesidad de una segunda transición en el ideario del Partido Socialista, la formación que durante más años ha ostentado el poder en el Estado español, para calcular hasta qué punto se ha convertido en una idea fuerza dentro del debate político y social en la segunda década de los años dos mil. De hecho, el marco de las elecciones generales de 2015, Pablo Iglesias, el líder de una de esas nuevas formaciones políticas (Podemos), publicó un ensayo titulado precisamente Una nueva Transición, materiales del año del cambio (2015). En las primeras elecciones como partido nacional y alentados por ese ideario regeneracionista de la vida pública española, crítico con las instituciones democráticas heredadas de la transición e insistiendo en su vínculo con los movimientos del 15-M, Podemos se situó como tercera fuerza política en el Congreso de los Diputados en 2015 y 2016.

Más allá del debate político, promotor y a la vez catalizador del debate social, las críticas a la Transición española desde la sociología, la politología, la historiografía o la historiografía cultural han sido más complejas y más completas. La ola de producción novelística sobre la memoria histórica a partir de los años 2000 (Martínez Rubio, 2015a), de hecho, se ha volcado en los últimos años y a medida que el debate social se intensificaba sobre los aspectos más controvertidos de la Transición con títulos de gran relevancia como: Anatomía de un instante (2009) o El impostor (2014) de Javier Cercas, El día de mañana (2011) de Ignacio Martínez de Pisón, Lección de anatomía (2008) o Daniela Astor y la caja negra (2013) de Marta Sanz, El jardín colgante (2012) de Javier Calvo, Twist (2013, 2011 en euskera) de Harkaitz Cano, Todo lejos (2014) de Alfons Cervera, Paseos con mi madre (2011) o Catalanes todos (2014) de Javier Pérez Andújar, Todo está perdonado (2011) o Un árbol caído (2015) de Rafael Reig, o ensayos de carácter divulgativo de gran tirada como el del novelista Antonio Muñoz Molina Todo lo que era sólido (2013) o el polémico CT o

\footnotetext{
Documento completo en: http://www.socialistasdelcongreso.es/opencms/export/sites/default/gps/resources/ Prensa/Documentos/141204 Solicitud Subcomisixn reforma Constitucixn.pdf http://politica.elpais.com/politica/2014/07/16/actualidad/1405522678_081334.html

Durante este periodo democrático ha habido otras propuestas de reforma de la Constitución. Cabe destacar en concreto la propuesta de Izquierda Unida en el año 2005 durante la primera legislatura del gobierno de José Luis Rodríguez Zapatero, donde pedía también una reorganización territorial, amén de otras cuestiones dispares como la sucesión de la Monarquía, la supresión de las circunscripciones por provincias como paso previo a una ley de reforma electoral, extensión del voto a los extranjeros residentes en España, la inclusión del suelo urbanizable como riqueza nacional subordinada al interés general del país (artículo 128), etc.
} 
Cultura de la Transición: crítica a 35 años de cultura española (2012), un compendio de estudios coordinados por Guillem Martínez.

Si la Transición ha estado en el punto de mira de los debates políticos y de los debates culturales en los últimos años, como resulta evidente a la luz de los ejemplos propuestos, las distintas representaciones han girado en torno a conceptos difusos y confusos que cabría poner en claro: pacto de silencio, pacto de olvido o desencanto. En el año 2000, a los veinticinco años de la muerte de Franco, la revista Quimera preparó un dossier monográfico sobre el tema al que llamó de forma premonitoria "Anatomía de la Transición"; entre otro artículos, el de Eduardo Subirats destacaba por su beligerancia contra el "enflaquecimiento de la memoria" y la cerrazón de ministerios e universidades a toda "discusión reflexiva en torno al nacionalcatolicismo español, las tradiciones simbólicas que heredaba del pasado, sus relaciones con los fascismos europeos y la persistencia de sus mitos y sus principios en el interior de la apertura liberal que habían orquestado los partidos políticos" (Subirats, 2000: 22).

A mi juicio, Subirats establece una equiparación errónea entre universidades y ministerios que impide avanzar en la detección de las fallas de la Transición. La Guerra Civil, según las estimaciones de Antonio Calzado Aldaria (2007), es el acontecimiento más estudiado por la historiografía moderna, por lo que se puede entender que las universidades en sus diferentes ramas del conocimiento sí habrían llevado a cabo su labor de revisión crítica ${ }^{10}$. El problema radicaría, entonces, no en las "universidades" (con todas sus contradicciones) sino en los "ministerios", e incumbiría a otros conceptos distintos del concepto de "historia". Como distingue de manera lúcida Ricard Vinyes, existen diferentes tratamientos de la historia por parte del Estado: "política pública de la memoria", "memoria pública" y "memoria oficial" (Vinyes, 2013: 1040)"11, esto es, en primer lugar el derecho a las distintas memorias garantizado y promovido por el Estado, en segundo lugar el debate sobre el pasado común en el que convergen y se confrontan distintas memorias en distintas coyunturas históricas y, por último, el relato oficial legitimador de los poderes institucionales elaborado por el propio Estado.

Siguiendo esta diferencia, Ricard Vinyes afirma que el déficit de atención de España respecto a su pasado no es un asunto de historia, de conocimiento o de universidad, sino de memoria o de sentido ético del pasado por parte de los poderes públicos:

La demanda de memoria [de la sociedad española] no es una demanda de conocimiento histórico académico, profesional. Esta expresión coloquial y popular que se ha instalado entre nosotros 'recuperar la memoria histórica' no es otra cosa que una metáfora social que expresa un desacuerdo moral, una insurrección ética, ante este modelo de impunidad y sus consecuencias en la construcción del relato fundacional que sobre nuestra democracia han mantenido los sucesivos gobiernos desde 1977 en España, y desde 1980 en Cataluña. (Vinyes, 2013: 1036)

Hay un desacuerdo moral con el tratamiento del pasado; no un olvido de la historia, sino una insurrección cultural (política, social o literaria) ante un concepto más concreto: la impunidad. En este sentido, Vinyes destaca los vasos comunicantes que

10 Aun con alarmantes excepciones, tales como el entramado criminal del robo de niños durante el franquismo y más tarde durante la democracia.

11 http://revistes.ub.edu/index.php/ACS/article/viewFile/10369/13159 
existen entre la operación de política pública de la memoria que pretende "privatizar" todo hecho del pasado, el silencio durante los sucesivos gobiernos democráticos con respecto a los crímenes de lesa humanidad y la impunidad hacia los genocidas, torturadores y represores franquistas.

La reclusión de la memoria a la esfera privada conlleva la negativa a crear un espacio público de diálogo y resignificación de memorias. Cuando estas resignificaciones o reinterpretaciones no pueden elaborarse porque son confinadas a la esfera estrictamente privada y personal, las trayectorias individuales se vuelven ininteligibles, incomprensibles, y la persona no logra reconocer la historia de su vida en la historia de su país. Privatizar no es otra cosa que extraer la memoria de la historia y despojarla de sentido, anular su presencia en el esfuerzo colectivo, su valor en la memoria colectiva, y evitar el reconocimiento de la huella humana en las instituciones. (Vinyes, 2013: 1041)

Quisiera detenerme en el concepto de "privatización" y analizarlo en el debate literario sobre la recuperación de la memoria histórica. Esta privatización de la memoria impide que el Estado arbitre en la esfera pública un debate memorialístico donde las distintas partes puedan construir un relato coral conflictivo pero conjunto. Este fenómeno de privatización de la memoria ya fue estudiado a través de los textos literarios por Raquel Macciuci (2010), según la cual el franquismo desde los años sesenta impuso una visión de la Guerra Civil alejada del mito de la Cruzada Nacional y más cercana al mito de Caín y Abel mediante el cual las dos Españas estaban llamadas a enfrentarse e intentar matarse una a otra; la guerra, por lo tanto, pasaba de ser deseable e higiénica a ser inevitable, y como todo lo inevitable, toda responsabilidad derivada de ello queda perdonada, como de hecho quedó perdonada a nivel jurídico con la Ley de Amnistía de 1977. Fernando Larraz en su ensayo Letricidio español (2014) llega a las mismas conclusiones que Macciuci al estudiar los mecanismos de censura durante el franquismo: en el caso de la narrativa sobre la Guerra Civil, la contienda es vista en un primer momento como heroica en las obras que pueden publicarse dentro del país, y a partir de los años cincuenta y sesenta, la guerra pasa a ser un asunto privado, familiar, descontextualizado y ahistórico, y por lo tanto un acontecimiento trágico donde se desvanece toda responsabilidad política. Las representaciones de la guerra, entonces, se elaborarían con una fuerte carga mítica y simbólica, prescindiendo de los condicionantes históricos que la provocaron; la privatización de la memoria (la memoria familiar, en especial) fabularía sobre esta carga mítica fuertemente deshistorizada.

Precisamente la privatización de la memoria es la postura que defiende Javier Cercas en El impostor (2014) al afirmar que:

La historia deben hacerla los historiadores, no los políticos, y la memoria la hace cada uno, y porque una ley de este tipo recuerda embarazosamente los métodos de los Estados totalitarios, que saben muy bien que la mejor manera de dominar el presente es dominar el pasado. (Cercas, 2014: 304)

Aludo al autor y no al narrador porque este fragmento de la novela corresponde en realidad a un artículo publicado en El País, crítico con la Ley de Memoria Histórica del Partido Socialista en 2007 y que se titula precisamente "La tiranía de la memoria". Cercas añade: 
La memoria es un ingrediente de la historia, no la historia: uno de los riesgos de convertir la memoria en historia -uno de los riesgos de las llamadas Leyes de Memoria- consiste en la creciente inclinación a escribir la historia desde el punto de vista exclusivo de las víctimas, cuando la historia de las víctimas es apenas una parte de la historia, que sólo empieza a completarse con la historia de los verdugos: una no existe sin la otra, ni se explica sin la otra. La historia pierde así su función de reconstructora objetiva del pasado al subordinarse a la memoria; la propia memoria pierde su función de vínculo vivo con la reivindicación de justicia que la anima, de recurso de los vencidos de la historia, y al institucionalizarse puede convertirse en la coartada del terror: la memoria manipulada del Holocausto es una de las justificaciones de las salvajadas del Gobierno israelí; más cerca: la memoria manipulada del franquismo es una de las justificaciones de las salvajadas de ETA. El historiador es no es un ideólogo. El historiador no es un político. El historiador no es un juez. El historiador no es nada más que un historiador. (Cercas, 2008) ${ }^{12}$

La manipulación de la memoria o su uso perverso en los casos de ETA o de los sucesivos gobiernos israelíes le llevan a Cercas a tomar partido por el discurso histórico de los historiadores, de manera "objetiva". Sin embargo, esta virtud de la objetividad fue ya cuestionada por las teorías metahistoriográficas de Hayden White (1973), según las cuales toda escritura de la historia se realiza en tanto que relato y no puede prescindir de un sujeto que ordena y explica el pasado desde sus condicionantes subjetivos. Me resulta paradójica la decisión de Cercas, quien se ha caracterizado desde Soldados de Salamina (2001) por revitalizar en la esfera pública los debates sobre el pasado traumático en España trascendiendo lo meramente literario, e incluso tensando de nuevo la fecunda relación que mantienen historia y ficción. Confunde, a mi entender, las políticas públicas de memoria, que es lo que hace el Estado al promulgar la Ley de Amnistía de 1977 o la Ley de Memoria Histórica de 2007 (clausurar o permitir el flujo de discursos a nivel institucional), con la memoria colectiva, de la que precisamente Cercas ha participado de manera enconada y exitosa (un debate social, cultural, histórico, con incidencia en la vida política) o peor, con la memoria oficial, que es aquella de la Guerra Civil como inevitable, la Transición como modélica y el recuerdo de las víctimas sin que se haga justicia con los victimarios.

En última instancia, esa memoria privada no colma ni interés ni el anhelo de reparación de buena parte de la sociedad española. Tampoco la historia que reclama Cercas. De haberlo hecho, no existiría esta perentoria "necesidad de memoria". Y si volvemos la vista de la Guerra Civil y el franquismo al interés de la sociedad española por la Transición, las coordenadas del escritor confunden por completo toda voluntad de interpretación crítica. Sí lo hace, en cambio, la reflexión de Ricard Vinyes en torno a esa operación cultural de privatización al enfrentarse a uno de los tópicos más extendidos sobre el proceso histórico: el pacto de silencio o el pacto de olvido.

Los comisarios de la exposición En Transición, realizada en el Centro de Cultura Contemporánea de Barcelona (Noviembre de 2007) y en el Centro Fernán Gómez, de Madrid (Septiembre de 2008) comprobamos que parte importante de su éxito consistió en que muchos visitantes se reconocieron participantes y protagonistas

Cito por: http://elpais.com/diario/2008/01/02/eps/1199258808_850215.html 
del lejano y complejo proceso de democratización del país: "ellos estaban allí,, eran históricos, su vida estaba en la historia de la nueva ciudadanía, su memoria se desplazaba del ámbito privado y entraba en el espacio público del que nunca debió haber salido: "lo que yo me pregunto es por qué no he sido capaz de explicar a mi hija todos aquellos años de cambios y movilizaciones en los que participé, y que han sido también cambios en mi vida, mi madurez; pero aún estoy a tiempo". Este era el comentario que uno de los visitantes dejó grabado en el vídeo en el que cualquiera podía exponer reflexiones sobre la muestra para ser debatidas públicamente en el acto de clausura de la exposición; y ésta fue una de las ideas más repetidas, “¿Por qué no lo he contado?”. El silencio no era olvido, más bien era el resultado de una privatización inducida de la memoria, un escenario que no sólo rompe todos los vínculos entre individuo e historia, sino también entre responsabilidad y política, lo que resulta más grave porque reduce los ciudadanos a clientes (¿electores?) (Vinyes, 2013: 1041-42)

Vinyes rompe con uno de los grandes mitos de la transición: no hubo pacto de olvido. Y transmuta el hipotético "pacto de silencio" por un concepto mucho más refinado como el de "privatización inducida de la memoria". De hecho, con respecto al silencio, nunca cesaron las novelas sobre el conflicto bélico ni tampoco sobre el franquismo. Y hubo quien tuvo ocasión de contar la Transición que se estaba haciendo: es el caso de Manuel Vicent a través de sus Crónicas parlamentarias (1984):

En la calle los guardias con travestí de antidisturbios daban una tonalidad dramática al festejo. [...] Pero en la calle no hubo nada. El bautizo, la boda o la confirmación de la democracia se celebraba dentro del caserón de las Cortes, donde a las doce menos diez minutos los nuevos senadores y diputados, vestidos de padrinos o de testigos de unas escrituras, ya estaban sentados y dispuestos a recibir el sacramento de la sagrada constitución. Los primeros en llegar fueron los comunistas, muy circunspectos, como queriendo indicar que a ellos nadie les cierra la puerta ni les pilla el sitio. Los más sueltos de ademán eran sin duda los de Alianza Popular, que esos se saben la casa así y tienen, como quien dice, el wiski todavía sin terminar en la barra del bar desde la última sesión orgánica y serían capaces de encontrar algún dictamen franquista perdido bajo un escaño. (Vicent, 1984)

Y también hubo quien tuvo ocasión de cuestionarla, sobre todo con la lucidez de Manuel Vázquez Montalbán, quien a principios de los ochenta fue capaz de formular todas estas preguntas a "gente inquietante" (Vázquez Montalbán, 1984): "Si la aristocracia estuviera en peligro, ¿te sumarías a una contrarrevolución?" (Vázquez Montalbán, 1984: 22) a Jesús Aguirre, duque de Alba; “Conspirabas?” (Vázquez Montalbán, 1984: 48) a José Mario Armero, presidente de la agencia de noticias Europa Press y uno de los mayores apoyos de Suárez en la legalización el PCE; "Para ti, ¿cuándo empieza a ser ilegítima la acción de ETA?” (Vázquez Montalbán, 1984: 71), a Juan Mari Brandés, diputado de la izquierda abertzale en el Congreso y firme defensor del diálogo con ETA como vía de solución al conflicto vasco; "Para usted, ¿un español es como un alemán o un australiano? [...] ¿Vive con pasión esa sensación de extranjería?" (Vázquez Montalbán, 1984: 86), a Heribert Barrera, histórico líder de Esquerra Republicana de Catalunya; “Ha muerto, pues, definitivamente, probablemente con la intentona del 23-F, el tipo de militar redentorista dispuesto a 
salvarnos a los españoles de nosotros mismos?" (Vázquez Montalbán, 1984: 98), a José Luis Cortina Prieto, uno de los militares juzgados y absueltos por el intento de golpe de Estado del 23-F; “¿Tú eres un invento de la Transición?” (Vázquez Montalbán, 1984: 107), a Carlos Ferrer Salat, fundador y presidente de la CEOE; “Sigue usted comprendiendo el golpismo?” (Vázquez Montalbán, 1984: 122) o “Por qué no le apartaron a usted con los demás: González, Carrillo, Gutiérrez Mellado, Suárez...?" (Vázquez Montalbán, 1984: 121), a Manuel Fraga Iribarne, ministro de Franco y fundador de Alianza Popular, el actual Partido Popular; “¿Qué es España?" (Vázquez Montalbán, 1984: 138) u "Horas después de decir lo que has dicho, ya en la soledad de tu madriguera, entre tus libros y tu música, colgada en el perchero de la casaca de Robespierre, ¿sigues creyendo en todo lo que has dicho?" (Vázquez Montalbán, 1984: 140), a Alfonso Guerra, vicepresidente del gobierno de España con el PSOE durante diez años; “¿A usted le parecía posible que un policía pilar de un régimen autoritario pudiera convertirse en garante del sistema democrático? [...] ¿Incluso recurriendo a policías torturadores? [...] Incluso recurrir a un [Roberto] Conesa?" (Vázquez Montalbán, 1984: 150), a Rodolfo Martín Villa, gobernador civil de Barcelona con Franco, ministro con la UCD y desde octubre de 2014 en búsqueda y captura internacional por crímenes de lesa humanidad; "La noche del 23-F, ¿temió usted una involución?” (Vázquez Montalbán, 1984: 246), “Usted se siente a gusto en esta España gobernada por socialistas", [... "El papa Woytila les parece un involucionista” (Vázquez Montalbán, 1984: 247), al Cardenal Tarancón, presidente de la Conferencia Episcopal Española entre 1971 y 1981; “¿Qué trato recibiste en prisión?” (Vázquez Montalbán, 1984: 256), al periodista de investigación Xavier Vinader, exiliado durante la democracia y condenado a prisión por inducción al homicidio al haber publicado un reportaje sobre la extrema derecha y la guerra sucia del Estado contra ETA.

El papel de la aristocracia en el golpe de Estado de 1936, el papel de los distintos agentes militares en el intento de golpe de Estado de 1981, las tensiones con el nacionalismo catalán en el nuevo Estado de las Autonomías, la guerra sucia contra ETA, el papel de la izquierda abertzale para la solución del conflicto vasco, la falta de depuración de los cuerpos y fuerzas de seguridad del Estado en la nueva democracia, la conversión de ministros franquistas en adalides democráticos de centro-derecha... sin duda no son cuestiones menores en esta crónica no tan sentimental de la Transición. Así las cosas, si hubo algún déficit de memoria, fue por la falta de respuesta a alguna de estas cuestiones por parte de las élites políticas, amparado además por el desarrollo del concepto de "reconciliación" en detrimento del concepto de "democracia" (Vinyes, 2013: 1037), lo cual situaba la guerra civil como matriz epistemológica de las nuevas fuerzas políticas, que debían reconciliarse de un pasado traumático, en lugar de dirimir ese pasado en una cultura capaz de expresar las diferentes memorias del conflicto. Educar en el conflicto y no en la reconciliación hubiera creado otro tipo de cultura política en España:

Gestionar los conflictos de memoria tiene dos posibilidades. La primera consiste en promover la ideología de la reconciliación (con sus retóricas del consenso). Pero esta opción ha generado lo que pretende evitar, esto es tensión, enojo, beligerancias diversas, atomización de las vindicaciones, y en especial la aparición de grupos y colectivos que apelan reparación para injusticias heterogéneas, que a menudo han sido generadas por el sistema social, no por la dictadura. La segun- 
da posibilidad consiste en asumir la existencia de conflictos entre memorias y sus respectivos relatos, crear una política pública que asuma la existencia de este conflicto, y promover un modelo instrumento destinado a implementar espacios públicos compartidos que ayuden al ciudadano a realizar trabajos de elaboración intelectual y emocional, y que puedan expresar, también en su dimensión simbólica, existencia del conflicto. En definitiva, reconocer y mediar. El problema no es que aparezcan todas las memorias, el problema es que el Estado no genera el marco de diálogo memorial reclamado, obteniendo con esta actitud y decisión la pérdida y la destrucción del patrimonio democrático. (Vinyes, 2013: 1042)

De hecho gran parte de la crítica al relato oficial de la Transición se centra en el concepto de "consenso" realizado a través de "élites políticas" (Martínez, 2012), que pretendían representar (o que representaban) a un país muy heterogéneo, en una coyuntura histórica violenta y con una tradición democrática republicana cercenada por cuarenta años de dictadura fascista.

Así pues, el debate político y cultural sobre la Transición despliega una retórica lastrada por tópicos que confunden en lugar de explicar. "Pacto de silencio" o "pacto de olvido" serían reducciones de un concepto más complejo como el de "privatización inducida de la memoria" o el de "impunidad". La emergencia de representaciones alternativas sobre este periodo pondrá en valor tales conceptos.

\section{El relato oficial y la crítica oficial de la Transición}

En los últimos años el relato convencional sobre la transición elaborado desde fines de los años setenta ha empezado a resultar insatisfactorio para públicos cada vez más amplios y exigentes. Aunque con distintos énfasis y matices, la idea común a toda esa literatura "oficial" es que la transición española a la democracia fue convenientemente pilotada desde arriba por elites organizadas en partidos políticos que fueron capaces de contener posibles estallidos sociales - en una época que era de crisis no sólo constitucional sino también económica- gracias al consenso alcanzado por las fuerzas de la oposición entre sí y con sectores de la vieja burocracia franquista que habían venido evolucionando hacia posturas prodemocráticas (Sánchez León, 2014: 71).

Recojo estas palabras de Pablo Sánchez León (2014) para ilustrar el marco conceptual en el que se ha venido desarrollando no solo el relato oficial de la Transición, sino gran parte de la crítica a ese relato oficial de la Transición. Una de las consecuencias positivas de estos límites del lenguaje es precisamente la interpretación que elaboran Eduardo Subirats, Ricard Vinyes o la lista de coautores del panfleto $C T$, $o$ Cultura de la Transición (2012), a partir de conceptos como "consenso", "reconciliación" y "élites" por oposición a "conflicto", "democracia" y "ciudadanía". Una de las consecuencias negativas, en cambio, ha sido la de ocultar bajo esa crítica a la superestructura de la Transición los nombres y rostros de otras luchas que parecen no existir en ese universo crítico.

Por ejemplo, el propio Pablo Sánchez León y Vicente Pérez Quintana coordinaron un volumen dedicado a las luchas ciudadanas entre el tardofranquismo y los albores de la democracia: Memoria ciudadana y movimiento vecinal. Madrid 1968-2008 
(2008). En este volumen, lejos de radiografiar la Transición como operación de élites (o yendo más allá de esta consideración), pusieron en valor las protestas y la acción política de las asociaciones de vecinos de las grandes ciudades españolas como elemento aglutinador de diferentes identidades urbanas que lucharon por transformar al menos el espacio concreto (muchas veces de exclusión) en el que vivían.

Sánchez León (2014) entendió que uno de los efectos de la instauración de la economía de mercado durante el franquismo, en la etapa del desarrollismo y de la apertura económica hacia el exterior, fue la creación de una mentalidad de consumo representada por la idea de una clase media de corte liberal:

El imaginario sociológico de la dictadura tenía por centro un discurso sobre las clases medias. Herencia de la cultura del liberalismo anterior a la Guerra Civil, dicho imaginario experimentó también una evolución en la dictadura, convirtiéndose en preciado objeto de reflexión, no sólo normativa sino también histórica, hasta desembocar en una novedosa identificación de la clase media con el conjunto de la sociedad, con el sujeto legítimo de una sociedad desarrollada. [...] Al ser la clase media una potencial 'suavizadora de las luchas clasiales', su extensión por el todo social la situaban por fin en la posición de 'ser la 'clase social' por antonomasia, el referente de toda la sociedad en conjunto. (Sánchez León: 2014: 80)

Esta identificación de la idea de clase media con desarrollo económico y cultural, protagonistas de la generación del 68, chocaba contra el totalitarismo de la dictadura, si bien no en sus aspectos económicos, sí en sus aspectos sociales y políticos. De ahí que la Transición se observara, antes de la muerte de Franco, como un futuro de promesas que cumplir. De ahí que la Transición se observara, una vez muerto Franco, como un periodo de "desencanto":

En muchos sentidos, las transformaciones que tuvieron lugar desde finales de los años cincuenta dejaron en las relaciones económicas y sociales una huella profunda que perdura hasta la actualidad: el predominio de una identidad de clase media que basa su estatus en el consumo y que, aunque reclama con constancia políticas de redistribución por parte del Estado, antepone la iniciativa de la Administración a la implicación política ciudadana. (Sánchez León, 2008: 14)

Rafael Reig recoge la idea del desencanto desde la óptica de la clase media en $U n$ árbol caído (2015):

Esa noche España fue derrotada en Eurovisión. Ganó Israel, y precisamente gracias a los votos españoles, en lo que la prensa calificó de 'admirable gesto de hidalguía'. Dos días después, la UCD obtuvo en las municipales una victoria pírrica, ya que, aunque fue el partido más votado, las principales ciudades acabaron en manos del PSOE, cuya mayoría absoluta de 1982 ya empezaba a columbrarse tras el encapotado horizonte del acoso y derribo del presidente Suárez. La abstención, sin embargo, aumentó, y se hablaba tanto del 'desencanto' que empezó a hacerse popular la frase 'contra Franco vivíamos mejor'. (Reig, 2015: 71)

Reig recoge algunos de los tópicos que más han circulado sobre la Transición, focalizado siempre sobre cierta idea de clase media, que bien pudiera hacer referen- 
cia de forma directa o indirecta al movimiento estudiantil (no en vano, la generación del movimiento estudiantil era aquella que por juventud y formación estaba llamada a construir intelectual y políticamente un nuevo país). Reig plantea incluso antes de 1982 la aparición del "desencanto", y en esta novela pone a discutir a personajes que son meros representantes dialécticos de las formaciones del momento: Alejando Urrutia, militante del PSOE, que vive en una urbanización de primera clase en uno de esos complejos urbanísticos del franquismo a las afueras de Madrid; Pablo Poveda, militante desencantado del PCE y escritor subvencionado por su mujer, ganador del Premio Planeta en los 80; Lola, la mujer que convive con Alejandro Urrutia, que se indigna y decide separarse de él la noche en que lo ve exageradamente eufórico por haber derrotado en una partida de ajedrez a Pablo Poveda. La significación de personajes y escenas es ramplona: el PSOE, representado por una "clase media" ilustrada y acomodada, derrota al PCE, representado por un escritor que cobrará prestigio en el plano literario pero no en el político, en una partida de ajedrez que se desarrollará a lo largo de toda la novela y que revelará un significado para Lola y para el investigador Johny.

Me atrevería a indicar que se ha codificado una crítica "oficial" a la Transición, del mismo modo que se criticaba la existencia de un "relato oficial" de la misma basado en el consenso, la reconciliación y la modernidad del país. Si bien Violeta Ros Ferrer (2014) al estudiar Anatomía de un instante (2009) detectaba cierta impostura en la crítica de Cercas a las distintas figuras que actuaron la noche del 23-F (entre las que no salen bien paradas ni el rey ni Felipe González, entre otros), lo mismo podríamos decir de los discursos "prototípicamente críticos" con la Transición. Esto viene a exponer Ros Ferrer:

En Anatomía de un instante los personajes que conforman la trama de la novela son las figuras públicas e icónicas ya conocidas por todos porque son parte de la historia aprendida: Suárez, Carrillo, Gutiérrez Mellado, Tejero, Juan Carlos I son, en definitiva, actores fundamentales del relato consolidado de la transición. Además de esto, la trama de la novela se demora en su totalidad en los entresijos del relato político e institucional. De este modo, el desvío que el texto de Cercas presenta con respecto al relato mítico - un relato que es, como decíamos, fundamentalmente estadocéntrico, en tanto que concentra la responsabilidad y el éxito del cambio político en España en el papel de la élite política y en el escenario del ámbito institucional- consiste, esencialmente, en ofrecer una versión diferente de las actuaciones de la élite dirigente y su responsabilidad o no en el golpe de Estado. Este gesto, sin embargo, no cuestiona, en sí, la perspectiva estadocéntrica del relato de la transición; es más, lo que se presenta como un desvío espectacular, al final de la novela viene a reafirmar y consolidar su versión más hegemónica. (Ros Ferrer, 2014: 245)

Si bien la crítca al proceso histórico se enmarca dentro de la conceptualización oficialista del relato de la transición y refuerza, por lo tanto, esa visión estadocéntrica y elitista del cambio histórico, por otro lado, el discurso crítico de Rafael Reig en Un árbol caído tiende a considerar la implicación política desde un punto de vista típicamente partidista y refuerza la tesis de Sánchez León sobre la "mesocracia" o la idea de "clase media" como clase absoluta que monopoliza tanto aspiraciones como relatos de un momento histórico concreto. La emergencia de memorias y represen- 
taciones alternativas, como las que estudiaban Sánchez León y Pérez Quintana en el movimiento vecinal, ofrecería un relato distinto y, sobre todo, una crítica distinta al relato oficial de la Transición.

En esta línea alternativa se enmarca la obra narrativa y cronística de Javier Pérez Andújar. Para el narrador de Milagro en Barcelona (2014), que no es sino el cronista identificable con el propio autor, el "desencanto" cobra un significado alternativo:

Del desencanto, ¿qué se hizo? A raíz de la muerte del presidente Adolfo Suárez y de la abdicación del rey Juan Carlos I, ambas en el año 2014, se ha hablado mucho de que hemos llegado al fin de la Transición; pero también en el mismo año ha tenido lugar otro suceso históricamente trascendental, que es la muerte del último de los hermanos Panero, el poeta Leopoldo María. Porque su desaparición nos indica que adonde hemos llegado es al fin no de la Transición sino del desencanto. Al mismo año 1976 pertenecen tanto la película El desencanto como la dimisión de Arias Navarro, último presidente del gobierno del régimen franquista. La Transición durará menos que el desencanto. En realidad la Transición duró lo que tardó en pasar de la libertad sin ira de Jarcha a la libertad de José Luis Perales, que era el nombre de un barco velero rodeado de gaviotas (Pérez Andújar, 2014: 26).

Pérez Andújar recupera la palabra clave de las clases medias: el desencanto, y la lleva más allá de la propia Transición, (con)fundiéndola con la democracia misma, a saber, un barco velero rodeado de gaviotas (como el logo del Partido Popular, el partido mayoritario de la derecha española). Pero tanto en Paseos con mi madre (2011) como en Milagro en Barcelona (2014), un libro cronístico de la periferia de Barcelona y los procesos migratorios contemporáneos, elaborado a medias con el fotógrafo Joan Guerrero, Pérez Andújar elaborará toda una mitificación de las clases bajas, de la clase obrera, de "los pobres" y escribirá desclasándose o apartándose de esa ideología de clase dominante, la clase media, para alumbrar el universo de "los pobres", y en concreto las luchas vecinales, de ayer en la Transición, y de hoy con la PAH (Plataforma de Afectados por la Hipoteca) y con los nuevos extranjeros, en una especie también de "segunda Transición":

Esta gente [los pobres, los emigrantes] viene a limpiar el discreto desencanto de la burguesía. A recoger los restos del naufragio y construir con los pecios un mundo nuevo. [...] Con la caída del desencanto, a la historia de España no le da tiempo ni de ser contemporánea, pues se desmorona y lo que queda alrededor son los infinitos solares de la prehistoria. Vivimos de nuevo en las cavernas de la democracia, viendo avanzar las sombras de viejos, terribles dinosaurios. Pero el desencanto fue un gesto de dandismo, una mueca de cansancio. Las gentes que retrataba Guerrero en aquellos años de aventura, en los descampados de las afueras, en las manifestaciones vecinales de los bloques, no eran los que se desilusionaron de la democracia. El hastío es un artículo de lujo. La gente pobre no se cansa de las cosas, solo se harta quien ya tiene. Se forjó el desencanto igual que la democracia, de arriba abajo. (Pérez Andújar, 2014: 25)

Esta visión “populista” de Javier Pérez Andújar (Martínez Rubio, 2015b) rompe con el discurso crítico dominante sobre los relatos de la Transición. El desencanto lo sintieron esas clases medias que delegaban su participación en un Estado fuerte, 
asistencial y autorreferencial. El desencanto en cambio no llegó a "los pobres", a las gentes que retrata Joan Guerrero y que viven en las periferias de las grandes ciudades y que llevarán a cabo la lucha vecinal. El concepto de "democracia", más allá del verticalismo del discurso repetido, adquiere un nuevo valor en Pérez Andújar, más optimista y más combativo, cuya reflexión parte de Paseos con mi madre (2011) y continúa en otras obras:

La democracia la fueron conquistando estos hombres y mujeres calle por calle, árbol por árbol. La democracia es una cosa que se puede tocar, y que esta gente tuvo en sus manos durante días seguidos y noches enteras. Conseguir un colegio público en un barrio que no lo tenía; la construcción de un ambulatorio donde no llegaban los médicos; dejar una plaza sin edificar para que los niños jueguen; hacer un polideportivo para que el único deporte no sea apedrear perros; lograr que pase el autobús por donde no pasaba nada o que llegue el metro a donde no llegaba para poder ir al trabajo sin necesidad de pisar charcos, sin aguantar la lluvia y el frío de la madrugada, sin andar por los descampados que separaban el barrio de los transportes públicos, esa es la democracia que hicieron realidad esas gentes encerrándose en los locales de sus asociaciones de vecinos, encadenándose a verjas, cortando el tráfico, protestando en la calle, luchando. (...)

Y todo esto que ya está, los ambulatorios, las bocas de metro, los colegios públicos..., es también lo primero que se pierde cuando desaparece la gente que los ha traído. Quienes llegan detrás creen que eso lo pone la naturaleza, como las hierbas y los saltamontes. Pero lo pone la política, y las cosas hay que conquistarlas permanentemente. Lo primero que ha quitado el Gobierno de Convergència al recobrar el poder ha sido eso: bocas de metro, guarderías, maestros y hospitales públicos, porque las personas que los pusieron o se han muerto o ya no están para defenderse. (Pérez Andújar, 2011: 58-59)

La democracia fue lo que consiguieron los vecinos de los bloques, de la periferia, cosas tangibles que deteriorarán la desmemoria y el abandono de las generaciones sucesivas. Pero será una nueva marginalidad, una nueva migración, una nueva pobreza, la que dé un nuevo impulso a la historia: "Los emigrantes son los operarios que manda la Historia para poner de nuevo en marcha la democracia” (Pérez Andújar, 2014: 99).

De modo que en Andújar encontramos las mismas correspondencias entre los años de la Transición y los años de la crisis económica o institucional actual que observábamos en las altas esferas de la política, en el discurso de la clase media y ahora en el discurso de las clases populares. Ahora bien, el concepto de democracia y aun el de Transición mismo recobran un nuevo significado: de lucha y de conquista por parte de los vecinos, de solidaridad y de conciencia sobre el territorio y de identidad periférica por parte de los ciudadanos ${ }^{13}$. Si la crítica oficial a la Transición venía a desacralizar el periodo entre el final de la dictadura y la recuperación de la democracia, sacralizado por el relato oficial, paradójicamente estos discursos populares de Javier Pérez Andújar o Pablo Sánchez León y Pérez Quintana vuel-

13 A propósito de territorio, memoria e identidades periféricas, véase el trabajo: "Cuarenta años de paz y cuarenta de aluminosis. Territorio, memoria e identidades periféricas en Paseos con mi madre de Javier Pérez Andújar", Artifara. Revista de lenguas y literaturas ibéricas y latinoamericanas, n. 16, 2016, pp. 335-346. 
ven a poner en valor la construcción democrática de la Transición en manos de las clases populares.

Coincidiendo con el deterioro del régimen franquista y los efectos de la "crisis del petróleo" de 1973, las asociaciones vecinales se sumaron a otros colectivos que desafiaban el poder establecido, de forma que las protestas de ámbito vecinal inundaron las calles y ocuparon las primeras páginas de los periódicos sobre todo en los meses que separan la muerte de Franco de la elaboración de la Constitución en 1978. El movimiento vecinal fue uno de los agentes clave en el desmoronamiento de la legitimidad de la dictadura. (Sánchez León, 2008: 14)

Así pues, conceptualizar la Transición unilateralmnte como una impostura o como un engaño o como una falsa democracia, olvidando esta otra Transición en los barrios obreros, se enmarca dentro de la postura en cierto modo snob que se corresponde con ese imaginario liberal forjado en el franquismo de una aspirante a clase media. Era propio del desencanto de los hermanos Panero, que no dejaban de ser una familia burguesa del régimen venida a menos.

\section{La última impostura}

Ya hemos visto que el concepto de democracia de Pérez Andújar durante los años de la Transición se contraponen a la idea burguesa del desencanto. Esa y otras ideas serán retomadas por Javier Cercas en su novela El impostor (2014). Esa impostura o esa condición de "impostor" se aplica a tres esferas bien distintas a lo largo de la obra. Unas veces se aplica a Enric Marco, el verdadero impostor (por mentiroso) de la memoria traumática: recordemos que Marco fue presidente de la Amical de Mauthausen en calidad de ex preso nazi, pero en 2005 se descubrió que nunca había permanecido en el campo de concentración en el que afirmaba haber estado recluido. Otras veces, la condición de "impostor" se aplica al propio narrador autoficticio por mezclar en un ejercicio de docuficción elementos, técnicas y estrategias (Schilschke y Schmelzer, 2010) tanto de la ficción como de la no ficción: no por casualidad el narrador vehicula con su investigación y con su discurso regresivo la historia del propio Enric Marco, de modo que no es la vida de Marco lo que se nos cuenta, sino al narrador autoficticio intentando comprender y contar la vida de Marco, lo que da pie a interpretaciones o "propuestas de sentido" (Martínez Rubio, 2015a) en base a hechos contrastados. Y por último, la figura del impostor se extiende por todo el periodo de la Transición, haciendo aparecer a todos los protagonistas como mentirosos de su propia historia y de su propio pasado.

Marco se inventó un pasado (o lo adornó o lo maquilló) en un momento en que alrededor de él, en España, casi todo el mundo estaba adornando o maquillando su pasado, o inventándoselo; Marco reinventó su vida en un momento en el que el país entero estaba reinventándose. (Cercas, 2014: 233)

La correspondencia que establece Cercas entre "invención del pasado" y Enric Marco está clara; el problema deviene en el momento de aplicar esa misma impos- 
tura al resto del país. Puede que los afectados por el desencanto también maquillaran su pasado. Está claro que buena parte de las élites políticas (especialmente en el partido de centro-derecha) sí lo hicieron, tal y como puso de manifiesto Manuel Vázquez Montalbán en sus entrevistas con gente inquietante. Pero no resulta tan evidente al observar la evolución de buena parte de la oposición al franquismo. No obstante, Javier Pérez Andújar aborda también la impostura de las clases dirigentes y ficcionaliza el proceso de conversión eucarística a la democracia de aquellos entusiastas del régimen franquista: en concreto, del nacionalismo conservador catalán. En Catalanes todos (2014), el escritor observa de qué manera Convergència i Unión ${ }^{14}$, el partido hegemónico del nacionalismo catalán de signo conservador, aprovecha para mudar la piel del franquismo a la democracia, y de qué manera está mudando la piel de nuevo en esta segunda transición hacia posiciones independentistas. Precisamente como representante de este partido, Ramona Codolls evidenciará en la novela la transubstanciación del ideario franquista en nacionalismo catalán conservador, y lo hará de manera esperpéntica:

Lo que más le gustaba a doña Ramona de El Corte Inglés era subir las escaleras mecánicas. Se le antojaba como ascender al cielo. La bajada, sin embargo, le producía vértigo. Dejándose llevar por aquella escaleras, cerró los ojos y se concentró en el más allá. Le habló una voz, a la que ella llamaba siempre "el presentimiento. -Ramona, hija, ya ves cómo se está poniendo Barcelona. No hay quien la reconozca. Cuánta gente viniendo de fuera. Y cuando más miserables, antes se hacen del Barça, que es el equipo de los señoritos. Pero espérate, porque esto es solo el comienzo. En poco tiempo pasará una cosa muy gorda. Bueno, te lo digo ya: a Franco le queda poco que estar entre vosotros. Y no veas cómo va a cambiar España. Pero no te asustes, que no va a haber otra guerra, El Caudillo lo deja todo atado y bien atado. Eso sí, tú no seas ilusa, hija. Si quieres que para ti todo siga como hasta ahora, vas a tener que espabilar y cambiar de campo en cuanto oigas el silbato. (Cercas, 2014: 192-93)

Y conforme avanza la novela, ya se le ve a Ramona Codolls en ese otro campo, el de los vencedores de todo y de siempre:

La vieja andaba con otras alborotando la calle... Dándole vivas a Jordi Pujol y a su mujer Marta Ferrusola, como si fueran Isabel y Fernando. [...] Al principio me alegré de ver a doña Ramona, pues ya le he dicho que la conozco de toda la vida. ¡Si su marido, que en paz descanse, y yo hasta habíamos fusilado juntos en el Campo de la Bota! [...] Le rogué que fuera generosa en ese día que parecía tan contenta: "¡Ramona!, con lo alegre que se la ve, que hasta parece que sea usted la que haiga (sic) ganado las elecciones en vez de Jordi Pujol” ¡Para qué me mordí la lengua! Cogió la mujer y empezó a gritarme como una histérica: “¡Sí, señor! ¡Tienes toda la razón! -me dijo- ¡Yo he ganado las elecciones! ¡Yo y no tú!”. (Cercas, 2014: 230-31)

14 Otro de los efectos de esa segunda transición es la aparición del Partido Demócrata Catalán, partido hegemónico del nacionalismo catalán nacido tras la refundación de Convergència Democràtica de Catalunya, integrante de la coalición de Convergència i Unió (CiU), ya liquidada. 
Como decía más arriba, la novela, además, va más allá proponiendo un nuevo cambio de piel de esta clase media: del franquismo al nacionalismo conservador, y del nacionalismo conservador al independentismo, como el giro político que en la última legislatura ha obrado buena parte de la coalición de CiU. Si bien Pérez Andújar detecta muy bien esa impostura ideológica en una clase social concreta, la clase media, aunque difusa en términos clásicos, Javier Cercas pretende extenderla al conjunto de la sociedad española para justificar la manera en que se llevó a cabo la Transición y justificar las decisiones que se tomaron durante el proceso (entre ellas la de la Ley de Amnistía del 77). Cercas, pese a la aparente subversión de los tópicos sobre la época (como el pacto de silencio), viene a reforzar la versión oficialista de la Transición:

Hubo un pacto de recuerdo, lo que explica que durante la Transición, todos o casi todos los partidos políticos se conjuraran para no repetir los errores que cuarenta años atrás había provocado la guerra civil. [...] Lo que en gran parte explica también que pudiera realizarse el inédito salto mortal consistente en pasar de una dictadura a una democracia sin guerra o sin grandes derramamientos de sangre y sin que desencadenase un conflicto inmanejable. (Cercas, 2014: 300)

Así pues, el golpe de Estado de Franco que dio comienzo a la guerra civil ${ }^{15}$ es calificado de "error". Pero lo significativo, además, es que encontramos otra vez en este relato el elemento que actúa como matriz del discurso: la guerra civil y la reconciliación ordenan el nuevo orden político.

El pacto del olvido es otro eufemismo, una manera de nombrar sin nombrar una de las principales carencias de la Transición, y es el hecho de que no se investigara públicamente y a fondo el pasado cercano ni se persiguieran los crímenes de la dictadura ni se resarciera por completo a la víctima. Las dos primeras cosas tal vez no podían haberse hecho en aquel momento sin dinamitar la democracia, o eso es lo que pensaron todos o casi todos los partidos políticos y todos o casi todos los españoles, que eligieron no hacer del todo justicia a cambio de construir una democracia. (Cercas, 2014: 300-301)

Hay un matiz que se pierde dentro del consabido discurso del "se hizo lo que se pudo"; como se ha visto, no es verdad que "todos o casi todos los españoles" eligieran no hacer del todo justicia a cambio de construir una democracia. Resulta comprometedor igualar las responsables de la ciudadanía y de las instituciones, aun comprendiendo los efectos y consecuencias de un sistema basado en la democracia representativa, en el caso de la impunidad sobre los crímenes de lesa humanidad del franquismo. La impostura se completa con la acusación general a la ciudadanía:

Si acaso, el silencio llegó más tarde, ya en los años ochenta, cuando a la derecha que procedía del franquismo y estaba en la oposición seguía sin interesarle hablar

Esta idea de golpe de Estado franquista como desencadenante de la guerra civil queda clara desde Soldados de Salamina (2001) hasta El monarca de la sombras (2017), en el que el autor regresa a la memoria familiar de la guerra. Cercas expresa así la responsabilidad del conflicto bélico. Y sin embargo, su posición política en El impostor (2014) lo lleva a contradecirse en esta idea. 
del pasado, porque solo tenía cosas que perder haciéndolo, y a la izquierda socialista que estaba en el poder dejó de interesarle hacerlo, porque haciéndolo no tenía nada que ganar. En cuanto a los demás, estábamos pendientes de disfrutar de nuestra limpia modernidad flamante de europeos ricos y civilizados como para ocuparnos de nuestra sucia historia inmediata de españoles harapientos y fratricidas. (Cercas, 2014: 301)

Esta visión pretendidamente crítica comete el pecado de equiparar a quien firmó una Ley de Amnistía con quien luchó por una boca de metro, una línea de autobús, un ambulatorio, un polideportivo, una decena de puestos de trabajo, etc. Esta es la idea defendida por Javier Pérez Andújar en sus novelas, pero también en sus reflexiones públicas:

Lo de la Transición me cansa. A mí me cansa lo de los buenos y los malos. Primero el discurso oficial, el discurso histórico, es que vamos, la Transición nuestra es tan buena que la venden en El Corte Inglés, vienen de todos los países a comprarla... bueno, es una exageración. Pero ahora están diciendo que era una mierda, y tampoco, hubo gente que se lo curró, hubo obreros que consiguieron que las calles de barro de sus barrios se convirtieran en parques y los bajos abandonados de los bloques se convirtieran en escuelas públicas, y en farmacias. Y esos obreros lo consiguieron entrando a trabajar a las cinco de la mañana, porque eran obreros, pero no acostándose esa noche porque empalmaban y estaban pegando carteles, haciendo asambleas, encerrándose en iglesias. [...] Pero hay una parte de la Transición que es una parte popular, una parte de la calle, y esa también existió. (Pérez Andújar, 2015: 145)

Del mismo modo, en El impostor Cercas arremete contra "la industria de la memoria", que crea artefactos o kitsch como pantalla para evitar hablar de los hechos reales, para escamotear la historia; en esta industria de la memoria incluye por supuesto al tejido de asociaciones por la recuperación de la memoria histórica que han ido articulándose durante la primera década de los 2000. De otro modo: estas reivindicaciones justas habrían contribuido a la banalización de la memoria. Dice Sebastiaan Faber (2015) al respecto:

A mí me parece que los grandes cambios que describe -el surgimiento de las demandas de justicia en torno a las fosas, las respuestas ante la crisis económica de 2009, así como la posibilidad de que en futuro próximo se exhumen las fosas o se repare a las víctimas- no obedecen a ningún fenómeno natural, coyuntural o demográfico. Dependen más bien de personas reales que cobren conciencia y se organicen. Es decir: dependen de la movilización de la sociedad civil. Es decir: de la democracia. Al atribuir el nacimiento del movimiento de la memoria a un fenómeno coyuntural y, en cambio, atribuir su hundimiento a los 'abusos' de la 'industria', Cercas no solo exime de responsabilidad al Estado y a la clase política, sino que se niega a reconocer el mérito y el valor democrático de los ciudadanos de a pie que se asociaron a partir de 2000 para lograr un cambio político que les hiciera justicia. Y, lo que es más grave, pierde de vista lo que esos actos de asociación tuvieron de regeneración democrática. 
Dentro de los discursos de la memoria aún hay espacio para el olvido. Quizás el lenguaje pegajoso y corredero no ayude tanto a explicar aquel momento histórico de la Transición, sino a cubrir con el velo de las palabras y los tópicos toda una realidad rescatable con la que podamos entroncar para afrontar (si es que estamos llamados a ello) una "segunda transición". De esta manera, convendría hacer emerger esas memorias alternativas capaces de desplazar el debate sobre la Transición fuera del marco cognitivo en que se ha venido desarrollando. El marco cognitivo en el que se elabora tanto el relato oficial como la crítica oficial de la Transición es igual de estadocéntrico y diluye del mismo modo responsabilidades (impunidades, silencios, olvidos y desencantos) entre instituciones, élites y ciudadanía. Se trata, en mi opinión, de una impostura más. O de la última impostura de los discursos críticos de la Transición.

\section{Obras citadas}

Calvo, Javier, El jardín colgante, Barcelona, Seix Barral, 2012.

Calzado Aldaria, Antonio: "Los historiadores de la Guerra Civil. La contienda fratricida es el acontecimiento más estudiado de la Historia”, en Albert Girona Albuixech; José Miguel Santacreu Soler, La Guerra Civil en la Comunidad Valenciana. La memoria de la Guerra Civil, vol. 18, Valencia, Editorial Prensa Valenciana, 2007.

Cano, Harkaitz, Twist, Barcelona, Seix Barral, 2013.

Cercas, Javier Soldados de Salamina, Barcelona, Tusquets, 2001.

Cercas, Javier, "La tiranía de la memoria”, El País, 02/01/2008. Consultable en: http://elpais. com/diario/2008/01/02/eps/1199258808_850215.html

Cercas, Javier, Anatomía de un instante, Barcelona, Literatura Random House, 2009.

Cercas, Javier, El impostor, Barcelona, Literatura Random House, 2014.

Cercas, Javier, El monarca de las sombras, Barcelona, Literatura Random House, 2017.

Cervera, Alfons, Todo lejos, Barceona, Piel de zapa, 2014.

Faber, Sebastiaan, “Javier Cercas y 'El impostor', o el triunfo del kitsch”, Frontera d, revista digital (2015), 12/02/2015. Consultable en: http://www.fronterad.com/?q=javier-cercas-y- $\%$ E2\%80\%98-impostor\%E2\%80\%99-o-triunfo-kitsch

Iglesias Turrión, Pablo, Una nueva Transición, materiales del año del cambio, Madrid, Akal, 2015.

Labrador Méndez, Germán, “¿Lo llamaban democracia? La crítica estética de la política en la transición española y el imaginario de la historia en el 15-M", Kamchatka. Revista de análisis cultural, 4 (2014), pp. 11-61 (Monográfico, Violeta Ros Ferrer (ed.), Contar la transición: discursos e imaginarios del cambio político en España).

Larraz, Fernando, Letricidio español. Censura y novela durante el franquismo, Gijón, Ediciones Trea, 2014.

Macciuci, Raquel, "La memoria traumática en la novela del siglo XXI. Esbozo de un itinerario", en Raquel Macciucci; María Teresa Pochat, Entre la memoria propia y la ajena. Tendencias y debates en la narrativa española actual, La Plata, Ediciones del lado de acá, 2010, pp. 17-49.

Martínez, Guillem [coord.], CT o Cultura de la Transición. Crítica a 35 años de cultura española, Barcelona, Mondadori, 2012.

Martínez de Pisón, Ignacio, El día de mañana, Barcelona, Seix Barral, 2011. 
Martínez Rubio, José, "Identidades enlazadas. Memoria, democracia e indignación: diálogos intergeneracionales en la España del siglo XXI", Olivar. Revista de literatura y cultura españolas, 20 (2013), pp. 245-267.

Martínez Rubio, José, Las formas de la verdad. Investigación, docuficción y memoria en la novela hispánica, Barcelona, Anthropos, 2015a.

Martínez Rubio, José, "Neobarroco popular. Humor, autobiografía y lenguaje en la obra narrativa de Javier Pérez Andújar", Confluenze. Rivista di studi iberoamericani, 7, 2, (2015b), pp. 107-119.

Martínez Rubio, José, “Cuarenta años de paz y cuarenta de aluminosis. Territorio, memoria e identidades periféricas en Paseos con mi madre de Javier Pérez Andújar", Artifara. Revista de lenguas y literaturas ibéricas y latinoamericanas, 16 (2016), pp. 335-346.

Muñoz Molina, Antonio, Todo lo que era sólido, Barcelona, Seix Barral, 2013.

Navarro, Vicenç, “La necesidad de una segunda Transición y una nueva Constitución”, Diario Público, 24/09/2012. Consultable en: http://blogs.publico.es/vicenc-navarro/2012/09/24/ la-necesidad-de-una-segunda-transicion-y-una-nueva-constitucion/

Pérez Andújar, Javier, Paseos con mi madre, Barcelona, Tusquets, 2011.

Pérez Andújar, Javier, Catalanes todos, Barcelona, Tusquets, 2014.

Pérez Andújar, Javier; Guerrero, Joan (2014), Milagro en Barcelona, Barcelona, Ariel, 2014.

Pérez Andújar, Javier, "Por definición si ganas, es que eres malo. Lo bueno es perder. Diálogos sobre la derrota con Javier Pérez Andújar", Confluenze. Rivista di studi iberoamericani, 7, 2, (2015), pp. 141-148.

Ramoneda, Josep, “Una nueva transición”, El País, 27/01/2013. Consultable en: http:/elpais. com/elpais/2013/01/24/opinion/1359044816_490828.html

Reig, Rafael, Todo está perdonado, Barcelona, Tusquets. 2015.

Reig, Rafael, Un árbol caído, Barcelona, Tusquets. 2015.

Ros Ferrer, Violeta, "Narrativa y transición: renovación y consenso en los discursos sobre la transición en la novela española", Kamchatka. Revista de análisis cultural, 4 (2014), pp. 233-251 (Monográfico, Violeta Ros Ferrer (ed.), Contar la transición: discursos e imaginarios del cambio político en España".

Sánchez León, Pablo, "Desclasamiento y desencanto. La representación de las clases medias como eje de una relectura generacional de la transición española”, Kamchatka. Revista de análisis cultural, 4 (2014), pp. 63-99 (Monográfico, Violeta Ros Ferrer (ed.), Contar la transición: discursos e imaginarios del cambio político en España).

Sánchez León, Pablo; Pérez Quintana, Vicente [coords.], Memoria ciudadana y movimiento vecinal. Madrid 1968-2008, Madrid, Los libros de la catarata, 2009.

Sanz, Marta, La lección de anatomía, Barcelona, Anagrama, 2008.

Sanz, Marta, Daniela Astor y la caja negra, Barcelona, Anagrama, 2013.

Subirats, Eduardo, "De la transición al espectáculo", Quimera, n.188 (2000), pp. 21-26.

Tschilschke, Christian, von Schmelzer, Dagmar (eds.), Docuficción. Enlaces entre ficción y noficción en la cultura española actual, Madrid/Frankfurt, Iberoamericana/Vervuert, 2010.

Vázquez Montalbán, Manuel, Mis almuerzos con gente inquietante, Barcelona, Planeta, 1984.

Vicent, Manuel, Crónicas parlamentarias, Madrid, Libertarias-Prodhufi, 1984.

Vinyes, Ricard, "Naturaleza y consecuencias del conflicto memorial en España. Entre la impunidad y la privatización", Anuari del conflicte social, Barcelona, Universitat de Barcelona, Observatori del conflicte social (2013), pp. 1025-1042.

White, Hayden, Metahistory: The Historical Imagination in Nineteenth-Century Europe, Baltimore, The Johns Hopkins University Press, 1973. 